\title{
Correction of spike contribution for strontium isotopic measurement by thermal ionization mass spectrometry: a test for spike-standard mixed solutions
}

\author{
Chang-sik Cheong ${ }^{1 *}$, Youn-Joong Jeong ${ }^{1}$ and Sung-Tack Kwon ${ }^{2}$
}

\begin{abstract}
Background: The Rb-Sr isotope system has long been used for radiometric dating and petrogenetic investigation. The concentrations of $\mathrm{Rb}$ and $\mathrm{Sr}$ could be precisely measured by isotope dilution thermal ionization mass spectrometry combined with chemical purification of these elements. For the simultaneous measurement of Sr isotopic composition and isotope dilution, the contribution from the added spike should be carefully corrected.

Findings: Reliable ${ }^{87} \mathrm{Sr} /{ }^{86} \mathrm{Sr}$ ratios of the spike-standard mixed solutions were obtained using the new mass bias factor calculated on the basis of measured $\mathrm{Sr}$ isotopic ratios. This correction yielded reasonable ${ }^{87} \mathrm{Sr} /{ }^{86} \mathrm{Sr}$ ratios for overspiked standard solutions whose spike fractions reaching $25 \mathrm{wt} . \%$.

Conclusions: The correction procedure described in this study shows that the simultaneous measurement of $\mathrm{Sr}$ isotopic composition and isotope dilution is available for the case that the spike proportion in the sample-spike mixture is significantly high $\left({ }^{84} \mathrm{Sr} /{ }^{86} \mathrm{Sr}>3.7\right)$. The principle of this correction protocol can also be applied to other isotope systems such as Sm-Nd and Lu-Hf pairs.
\end{abstract}

Keywords: Rb-Sr; Thermal ionization mass spectrometry; Isotope dilution; Spike contribution

\section{Findings}

Introduction

Rubidium-87 decays to stable ${ }^{87} \mathrm{Sr}$ by emission of $\beta^{-}$particle with a decay constant of $1.420( \pm 0.010) \times 10^{-11}$ years $^{-1}$ (Steiger and Jäger 1977) which corresponds to a half-life of $48.8 \times 10^{9}$ years. It is notable that this International Union of Geological Sciences-accepted decay constant is being considered to be high by $1 \%$ to $2 \%$ as summarized in Begemann et al. (2001). Rubidium and strontium belong to the groups IA and IIA, respectively. They are easily fractionated from each other through geological processes such as partial melting and igneous and metamorphic mineral growth. Therefore, the ${ }^{87} \mathrm{Rb}^{87} \mathrm{Sr}$ isotope system has long been used for radiometric dating and petrogenetic investigation (Faure and Mensing 2005).

\footnotetext{
* Correspondence: ccs@kbsi.re.kr

${ }^{1}$ Division of Earth and Environmental Sciences, Korea Basic Science Institute, Ochang, Chungbuk 363-883, Republic of Korea

Full list of author information is available at the end of the article
}

The traditional thermal ionization mass spectrometry (TIMS) is still regarded as the benchmark technique to measure $\mathrm{Rb}-\mathrm{Sr}$ isotope ratios. By TIMS, the inter-elemental ratio cannot be directly measured but is obtained through isotope dilution (Moore et al. 1973), a method of analyzing chemical substances by the addition of isotopically enriched spike to the sample. Considering the inhomogeneous distribution of $\mathrm{Rb}$ and $\mathrm{Sr}$ in most geological samples, simultaneous measurement of $\mathrm{Sr}$ isotopic composition and isotope dilution is essential. In this case, inevitable contribution from the spike should be carefully corrected.

This study evaluates the effectiveness of correction protocol to measure ${ }^{87} \mathrm{Sr} /{ }^{86} \mathrm{Sr}$ ratio in a series of mixture of ${ }^{84} \mathrm{Sr}$-enriched spike and standard solution. It has been tested whether a reasonable ${ }^{87} \mathrm{Sr} /{ }^{86} \mathrm{Sr}$ ratio could be obtained for overspiked standard solutions of which spike fractions reach $45 \mathrm{wt} . \%$. 


\section{Availability and requirements}

\section{Preparation of spike and standard solution}

The ${ }^{84} \mathrm{Sr}$-enriched isotope spike and standard solutions were prepared at the Korea Basic Science Institute (KBSI) in Ochang. In the following, all errors are quoted on the basis of $2 \sigma$ standard error, unless stated otherwise.

The spike, $\mathrm{SrCO}_{3}$ form, was provided by the Oak Ridge National Laboratory (batch number $=236,201$, order number $=65-0056$ ). It was dissolved in hot $10 \% \mathrm{HNO}_{3}$ and diluted to about $15 \mu \mathrm{g} / \mathrm{g}$ solution with $5 \% \mathrm{HNO}_{3}$. The AnApure ${ }^{\mathrm{TM}}$ ICP standard of $1,002( \pm 10) \mathrm{mg} / \mathrm{L} \mathrm{Sr}$ (lot no. AEP-130-726) was diluted to $21.480 \mu \mathrm{g} / \mathrm{g}$ solution in $2 \% \mathrm{HNO}_{3}$ (the specific gravity of $2 \% \mathrm{HNO}_{3}=$ $1.028 \mathrm{~g} / \mathrm{mL}$ ) and then was admixed with the spike solution. Ten mixed solutions were prepared with mixing proportions (spike/standard) ranging from about 1:1.2 to $1: 70$ in weight.

\section{Instrumental analysis}

The $\mathrm{Rb}-\mathrm{Sr}$ isotopic analysis was conducted by using a Phoenix (Isotopx) TIMS, Cheshire, CW, UK, installed at the KBSI. This instrument is equipped with eight movable Faraday collectors and one fixed axial channel where the ion beam intensities can be measured with either a Faraday collector or an ion counting Daly detector.

In this study, all required isotopes were simultaneously detected on Faraday collectors. The sensitivity on ${ }^{88} \mathrm{Sr}$ was typically around $3 \mathrm{~V}\left(10^{11} \Omega\right.$ resistors). The strontium isotope measurements of the standard and spike-standard mixed solutions were performed with a multi-dynamic mode (Lenz and Wendt 1976) in which the Faraday collectors were set to simultaneously detect ${ }^{84} \mathrm{Sr}$ (axial), ${ }^{86} \mathrm{Sr}$ (H2), ${ }^{87} \mathrm{Sr}(\mathrm{H} 3)$, and ${ }^{88} \mathrm{Sr}(\mathrm{H} 4)$ for the first static run, and ${ }^{84} \mathrm{Sr}$ (L2), ${ }^{86} \mathrm{Sr}(\mathrm{H} 1),{ }^{87} \mathrm{Sr}(\mathrm{H} 2)$, and ${ }^{88} \mathrm{Sr}$ (H3) for the second run. One measurement consists of 5 blocks of 12 cycles with an integration time of $10 \mathrm{~s}$. The mass bias was exponentially normalized to ${ }^{86} \mathrm{Sr} /{ }^{88} \mathrm{Sr}=$ 0.1194. The mean multi-dynamic ${ }^{87} \mathrm{Sr} /{ }^{86} \mathrm{Sr}$ acquired for NBS987 was $0.710252 \pm 0.000007(n=7)$ during the course of this study.

The isotopic composition of ${ }^{84} \mathrm{Sr}$-enriched spike was measured with a multi-static mode (100 cycles, 5 blocks, integration time $=10 \mathrm{~s})$ in which the Faraday collectors were set to detect ${ }^{84} \mathrm{Sr}$ (axial), ${ }^{86} \mathrm{Sr}(\mathrm{H} 2),{ }^{87} \mathrm{Sr}(\mathrm{H} 3)$, and ${ }^{88} \mathrm{Sr}(\mathrm{H} 4)$. In this measurement, the instrumental mass fractionation was not normalized.

\section{Results and discussion}

Five measurements for the ${ }^{84} \mathrm{Sr}$ spike yielded an average ${ }^{84} \mathrm{Sr} /{ }^{88} \mathrm{Sr}$ of $561.4 \pm 0.9,{ }^{86} \mathrm{Sr} /{ }^{88} \mathrm{Sr}$ of $0.7661 \pm 0.0010$, and ${ }^{87} \mathrm{Sr} /{ }^{88} \mathrm{Sr}$ of $0.1819 \pm 0.0030$, respectively. Therefore, the ${ }^{84} \mathrm{Sr}$ enrichment and atomic weight of the spike are calculated to be 83.9242 and 99.65 at.\%, respectively. Although the instrumental mass fractionation was not corrected during the TIMS measurement, this enrichment value is well matched with the suggested value $(99.64 \pm$ $0.01 \%$, Tracy 1999). The exponentially normalized multidynamic measurement of the $\mathrm{Sr}$ standard yielded an average ${ }^{87} \mathrm{Sr} /{ }^{86} \mathrm{Sr}$ ratio of $0.707630 \pm 0.000009(n=5)$.

The $\mathrm{Sr}$ isotope ratios measured for the spike-standard mixed solutions have been normalized to ${ }^{86} \mathrm{Sr} /{ }^{88} \mathrm{Sr}=$ 0.1194. This mass bias correction is not valid because the ${ }^{86} \mathrm{Sr} /{ }^{88} \mathrm{Sr}$ of the added spike was significantly shifted from the natural value through the enrichment processes from 0.1194 to 0.7661 . The first step for the correction of spike contribution is to determine a new mass bias factor $\left(\alpha_{\text {new }}\right)$ from the measured $\mathrm{Sr}$ isotope ratios. In the following, ' $s$ ' denotes the normal $\mathrm{Sr}$ standard, ' $t$ ' denotes the Sr spike, and ' $m$ ' and ' $c$ ' represent the measured and corrected values, respectively. The $(86 t / 86 s)$ can be calculated using $(84 / 86) m$, $(84 / 86) s$, and $(84 / 86) t$ :

$$
\begin{aligned}
\left(\frac{84}{86}\right)_{m} & =\frac{84_{s}+84_{t}}{86_{s}+86_{t}}=\frac{\frac{84_{s}}{86_{s}}+\frac{84_{t}}{86_{s}}}{1+\frac{86_{t}}{86_{s}}} \\
& =\frac{\left(\frac{84}{86}\right)_{s}+\frac{86_{t}}{86_{s}} \times\left(\frac{84}{86}\right)_{t}}{1+\frac{86_{t}}{86_{s}}} \\
\left(\frac{86_{t}}{86_{s}}\right) & =\frac{\left(\frac{84}{86}\right)_{m}-\left(\frac{84}{86}\right)_{s}}{\left(\frac{84}{86}\right)_{t}-\left(\frac{84}{86}\right)_{m}}, \\
\left(\frac{88_{t}}{88_{s}}\right) & =\frac{\frac{88_{t}}{86_{t}} \times 86_{t}}{\frac{88_{s}}{86_{s}} \times 86_{s}}
\end{aligned}
$$

Because the measured 84/86 ratio used in the above calculation has an uncertainty due to incorrect normalization to $86 / 88=0.1194$, the $86 t / 86 s$ should be recalculated after determination of the new mass bias factor (see below).

The $(86 / 88) s$ can be reduced by using $(86 / 88) m$, $(88 t /$ $88 s)$, and $(86 / 88) t$ :

$$
\begin{aligned}
& \left(\frac{86}{88}\right)_{m}=\frac{\left(\frac{86}{88}\right)_{s}+\frac{88_{t}}{88_{s}} \times\left(\frac{86}{88}\right)_{t}}{1+\frac{88_{t}}{88_{s}}} \\
& \left(\frac{86}{88}\right)_{s}=\left(\frac{86}{88}\right)_{m} \times\left(1+\frac{88_{t}}{88_{s}}\right)-\left(\frac{86}{88}\right)_{t} \times \frac{88_{t}}{88_{s}}
\end{aligned}
$$

The mass fractionation can now be accurately corrected using the calculated $(86 / 88) s$. The exponential law (Russel et al. 1978) yields a mass bias factor before $\left(\alpha_{\text {old }}\right)$ and after $\left(\alpha_{\text {new }}\right)$ the spike correction as the following:

$$
a_{\mathrm{old}}=\frac{\ln \left(\frac{0.1194}{\left(\frac{86}{88}\right)_{m}}\right)}{\ln \left(\frac{M_{86}}{M_{88}}\right)}, a_{\text {new }}=\frac{\ln \left(\frac{0.1194}{\left(\frac{86}{88}\right)_{s}}\right)}{\ln \left(\frac{M_{86}}{M_{88}}\right)},
$$

where ' $M$ ' denotes the mass of the isotope. 
Table 1 Correction results for the spike-standard mixed solutions

\begin{tabular}{|c|c|c|c|c|c|c|c|c|c|c|}
\hline & $86 / 88_{m}$ & $\% \mathrm{SE}$ & $84 / 86_{m}$ & $\% \mathrm{SE}$ & $84 / 86_{c}$ & $87 / 86_{m}$ & $\% \mathrm{SE}$ & $87 / 86_{s}$ & $2 \sigma \mathrm{SE}$ & Spike wt.\% \\
\hline Mix 1 & 0.12090 & 0.0068 & 8.4583 & 0.0050 & 8.5427 & 0.705574 & 0.0011 & 0.707582 & 0.000016 & 45.1 \\
\hline Mix 2 & 0.12034 & 0.0089 & 3.6918 & 0.0094 & 3.7076 & 0.706777 & 0.0009 & 0.707634 & 0.000013 & 25.9 \\
\hline Mix 3 & 0.12030 & 0.0048 & 2.4858 & 0.0051 & 2.4929 & 0.707068 & 0.0010 & 0.707640 & 0.000014 & 18.9 \\
\hline Mix 4 & 0.12032 & 0.0049 & 1.9667 & 0.0050 & 1.9711 & 0.707165 & 0.0009 & 0.707615 & 0.000013 & 15.5 \\
\hline Mix 5 & 0.11982 & 0.0179 & 1.5658 & 0.0187 & 1.5686 & 0.707292 & 0.0010 & 0.707644 & 0.000014 & 12.6 \\
\hline Mix 6 & 0.12016 & 0.0016 & 1.2043 & 0.0022 & 1.2059 & 0.707349 & 0.0010 & 0.707618 & 0.000014 & 9.9 \\
\hline Mix 7 & 0.11983 & 0.0034 & 0.7787 & 0.0030 & 0.7794 & 0.707469 & 0.0008 & 0.707638 & 0.000011 & 6.5 \\
\hline Mix 8 & 0.11976 & 0.0143 & 0.4234 & 0.0147 & 0.4236 & 0.707568 & 0.0010 & 0.707653 & 0.000014 & 3.4 \\
\hline Mix 9 & 0.12023 & 0.0185 & 0.2831 & 0.0103 & 0.2832 & 0.707593 & 0.0010 & 0.707646 & 0.000014 & 2.1 \\
\hline Mix 10 & 0.11983 & 0.0145 & 0.2071 & 0.0173 & 0.2072 & 0.707575 & 0.0010 & 0.707610 & 0.000014 & 1.4 \\
\hline Average $^{a}$ & & & & & & & & 0.707633 & & \\
\hline$S D^{a}$ & & & & & & & & 0.000015 & & \\
\hline $2 \sigma S E^{a}$ & & & & & & & & 0.000010 & & \\
\hline
\end{tabular}

${ }^{\mathrm{a}}$ The result of mix 1 is excluded.
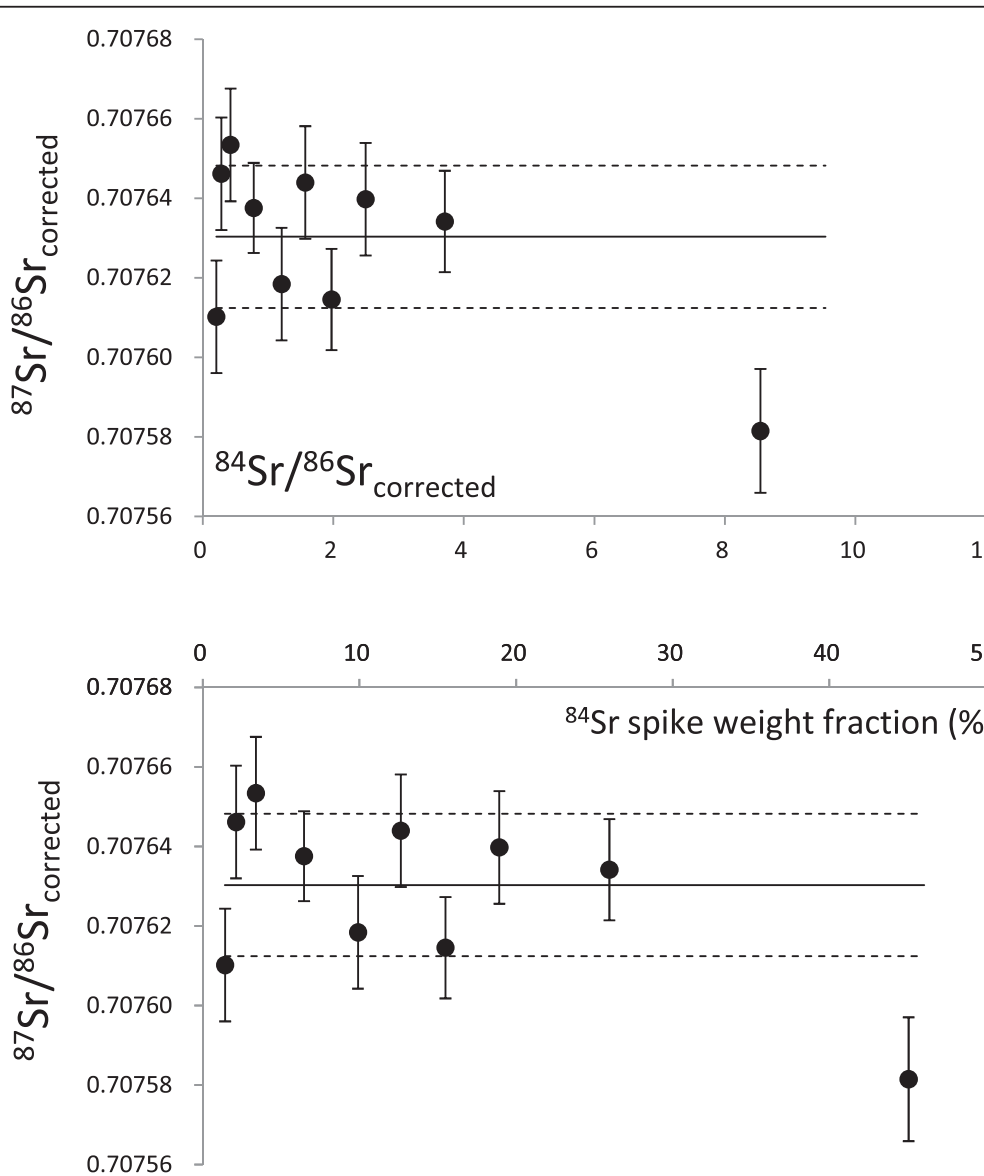

Figure 1 Plots of corrected ${ }^{87} \mathrm{Sr} /{ }^{86} \mathrm{Sr}$ as a function of ${ }^{84} \mathrm{Sr} /{ }^{86} \mathrm{Sr}$ and weight fractions of the spike. Solid and dashed lines represent an average ${ }^{87} \mathrm{Sr}{ }^{86} \mathrm{Sr}$ and $2 \sigma$ standard deviation of the unspiked standard data, respectively. Error bars are based on within-run $2 \sigma$ standard error. 
The newly corrected (84/86) ratio used for isotope dilution is yielded as the following:

$$
\begin{aligned}
& \left(\frac{84}{86}\right)_{\text {instrumentally measured }}=\left(\frac{84}{86}\right)_{c(\text { old })} \times\left(\frac{M_{86}}{M_{84}}\right)^{\alpha_{\text {old }}} \\
& \left(\frac{84}{86}\right)_{c(\text { new })}=\left(\frac{84}{86}\right)_{\text {instrumentally measured }} \times\left(\frac{\mathrm{M}_{84}}{\mathrm{M}_{86}}\right)^{\alpha_{\text {new }}}
\end{aligned}
$$

The newly corrected (84/86) ratios of the ten mixed solutions yielded a mean $\mathrm{Sr}$ concentration of $15.271 \pm$ $0.031 \mu \mathrm{g} / \mathrm{g}$ for the ${ }^{84} \mathrm{Sr}$-enriched spike prepared in this study.

Also, the $(87 / 86) c$ can be newly calculated using measured $\mathrm{Sr}$ isotope ratios as the following.

$$
\begin{gathered}
\left(\frac{87}{86}\right)_{c \text { (new) }}=\left(\frac{87}{86}\right)_{\text {instrumentally measured }} \times\left(\frac{\mathrm{M}_{87}}{\mathrm{M}_{86}}\right)^{\alpha_{\text {new }}} \\
\text { Actually, }\left(\frac{87}{86}\right)_{\text {instrumentally measured }} \\
=\left(\frac{87}{86}\right)_{c \text { (old) }} \times\left(\frac{\mathrm{M}_{86}}{\mathrm{M}_{87}}\right)^{\alpha_{\text {old }}}
\end{gathered}
$$

Finally, the $(87 / 86) c$ (new) is used for the calculation of the $(87 / 86) s$ :

$$
\begin{aligned}
& \left(\frac{87}{86}\right)_{s}=\left(\frac{87}{86}\right)_{c(\text { new })} \times\left(1+\frac{86_{t}}{86_{s}}\right)-\left(\frac{87}{86}\right)_{t} \times \frac{86_{t}}{86_{s}} \text { because }\left(\frac{87}{86}\right)_{m} \\
& =\frac{87_{s}+87_{t}}{86_{s}+86_{t}}=\frac{\frac{87_{s}}{86_{s}}+\frac{87 t}{86 s_{s}}}{1+\frac{86 \sigma_{s}}{86_{s}}}=\frac{\left(\frac{87}{86}\right)_{s}+\frac{86_{t}}{86_{s}} \times\left(\frac{87}{86}\right)_{t}}{1+\frac{86}{866_{s}}} \quad \text { (it is noted }
\end{aligned}
$$

that $86_{t} / 86_{s}$ can be recalculated on the basis of newly corrected 84/86).

Table 1 summarizes the spike correction results for the ten spike-standard mixed solutions. The corrected ${ }^{87} \mathrm{Sr} /{ }^{86} \mathrm{Sr}$ ratios of the mixed solutions are displayed in Figure 1 with the measured values of the unspiked standard. As shown in Figure 1, the protocol described in this study successfully corrected the spike contribution in the case that the spike fraction in the mixture reaches 25 wt.\% $\left.{ }^{84} \mathrm{Sr} /{ }^{86} \mathrm{Sr}_{\text {mixture }}>3.7\right)$. It is not clear why the corrected ${ }^{87} \mathrm{Sr} /{ }^{86} \mathrm{Sr}$ ratio for mix 1 solution (spike fraction $=45.1 \mathrm{wt} . \%$ ) deviates from the unspiked standard value. The corrected ${ }^{87} \mathrm{Sr} /{ }^{86} \mathrm{Sr}$ ratios of nine mixed solutions (mix 2 to mix 10) yield an indistinguishable average of $0.707633 \pm 0.000010$ from the unspiked value $(0.707630 \pm 0.000009)$. There is no trend between the corrected ${ }^{87} \mathrm{Sr} /{ }^{86} \mathrm{Sr}$ and the spike fraction (or ${ }^{84} \mathrm{Sr} /{ }^{86} \mathrm{Sr}_{\text {mixture }}$ ) in the range from 1.4 to $25.9 \mathrm{wt} . \%$. It is noted that the principle of this correction protocol can also be applied to other isotope systems such as Sm-Nd and Lu-Hf pairs, as briefly interpreted in the study of Cheong and Kwon (2010).

\section{Competing interests}

The authors declare that they have no competing interests.
Acknowledgements

This study was supported by the KBSI grant (G34200).

\section{Author details}

${ }^{1}$ Division of Earth and Environmental Sciences, Korea Basic Science Institute, Ochang, Chungbuk 363-883, Republic of Korea. ${ }^{2}$ Department of Earth System Sciences, Yonsei University, Seoul 120-749, Republic of Korea.

Received: 17 January 2014 Accepted: 12 February 2014

Published online: 23 April 2014

\section{References}

Begemann F, Ludwig KR, Lugmair GW, Min K, Nyquist LE, Patchett PJ, Renne PR, Shin CY, Villa IM, Walker RJ (2001) Call for an improved set of decay constants for geochronological use. Geochim Cosmochim Acta 65:111-121

Cheong CS, Kwon ST (2010) Calibration of Sm-Nd mixed spike by Teflon powder method. J Anal Sci Tech 1:30-36

Faure G, Mensing TM (2005) Isotopes: Principles and applications, 3rd edn. John Wiley \& Sons, Hoboken

Lenz H, Wendt I (1976) Use of a double collector for high-precision isotope ratio measurements in geochronology. Adv Mass Spectrom 7A:565-568

Moore LJ, Moody JR, Barnes IL, Gramlich JW, Murphy TJ, Paulsen PJ, Shields WR (1973) Trace determination of rubidium and strontium in silicate glass standard reference materials. Anal Chem 45:2384-2387

Russel WA, Papanastassiou DA, Tombrello TA (1978) Ca isotope fractionation on the earth and other solar system materials. Geochim Cosmochim Acta 42:1075-1090

Steiger RH, Jäger $E$ (1977) Subcommission on geochronology: convention on the use of decay constants in geo- and cosmochronology. Earth Planet Sci Lett 36:359-362

Tracy JG (1999) High-purity enrichment of ${ }^{84}$ Sr. Nucl Instrum Methods Phys Res Sect A 438:1-6

\section{doi:10.1186/s40543-014-0026-1}

Cite this article as: Cheong et al:: Correction of spike contribution for strontium isotopic measurement by thermal ionization mass spectrometry: a test for spike-standard mixed solutions. Journal of Analytical Science and Technology 2014 5:26.

\section{Submit your manuscript to a SpringerOpen ${ }^{\circ}$ journal and benefit from:}

- Convenient online submission

- Rigorous peer review

- Immediate publication on acceptance

- Open access: articles freely available online

- High visibility within the field

- Retaining the copyright to your article

Submit your next manuscript at $>$ springeropen.com 